INGENIO WORKING PAPER SERIES

Ingenio CEIC-UPV

INSTITUTO DE GESTIÓN DE LA INNOVACIÓN Y DEL CONOCIMIENTO

Measuring personal networks and their relationship with scientific

production

Africa Villanueva-Felez, Jordi Molas-Gallart, Alejandro Escribá Esteve

Working Paper No 2011/11

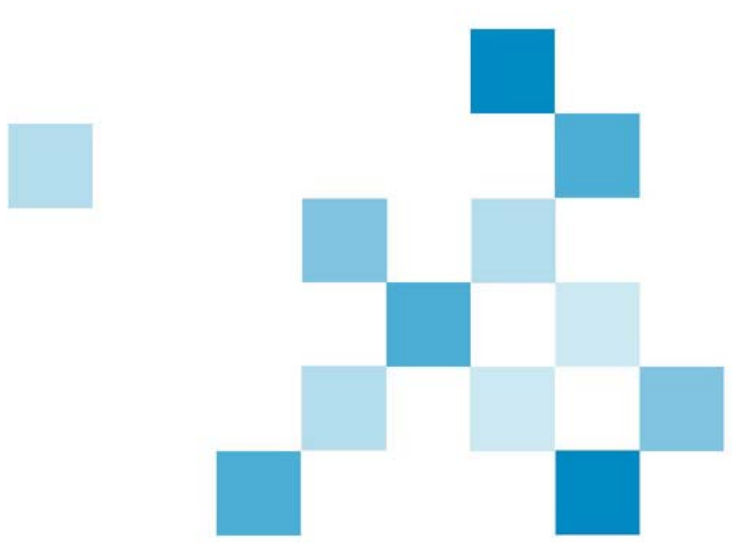




\title{
Measuring Personal Networks And Their Relationship With Scientific Production ${ }^{1}$
}

\author{
a INGENIO (CSIC-UPV), Valencia (Spain) \\ Email: africa.villanueva@ingenio.upv.es \\ ${ }^{\mathrm{b}}$ Department of Management, \\ Universidad de Valencia (Spain)
}

Africa Villanueva-Felez ${ }^{\mathrm{a}}$, Jordi Molas-Gallart ${ }^{\mathrm{a}}$, Alejandro Escribá Esteve ${ }^{\mathrm{b}}$

Keywords: embeddedness, academic network, research output

\begin{abstract}
The analysis of social networks has remained a crucial and yet understudied aspect of the efforts to measure Triple Helix linkages. The Triple Helix model aims to explain, among other aspects of knowledge-based societies, "the current research system in its social context" (Etzkowitz \& Leydesdorff, 2000:109). This paper develops a novel approach to study the research system from the perspective of the individual, through the analysis of the relationships among researchers, and between them and other social actors. We develop a new set of techniques and show how they can be applied to the study of a specific case (a group of academics within a university department). We analyse their informal social networks and show how a relationship exists between the characteristics of an individual's network of social links and his or her research output.
\end{abstract}

\footnotetext{
${ }^{1}$ Part of the work that has led to this article was supported by a grant from the Spanish National R\&D Plan (Project ref.: SEJ2005-05923/EDUC). We would also like to thank Ruddi Bekkers and Pablo d'Éste.
} 


\section{Introduction}

The Triple Helix model puts forward the notion that innovation is generated through a complex pattern of interaction among industries, universities and governments. Etzkowitz et al. (2000) argue that these institutional spheres are increasingly interwoven with linkages emerging at various stages of the innovation and policy processes. Social networks are central to Triple Helix linkages and their development is a frequent policy objective. Consequently, the establishment of networks can be considered both as one of the processes through which knowledge flows among actors, and also as an outcome of the policies oriented to the reinforcement of these flows (Molas-Gallart et al., 2000).

Yet, despite their importance, social networks are considerably difficult to analyse and measure. It is understandable that the efforts to define and collect indicators of university-society relationships (the so-called Third Mission indicators) have focused on clearly identifiable inputs (number of employees in technology transfer, investments in spin-offs, etc.), and outputs (for instance, commercialisation indicators like the income from licences) of these processes. The analysis of social networks may be a crucial yet undervalued method for measuring Triple Helix linkages and developing innovative indicators.

Some relevant efforts have been made from the Social Network Perspective, which have studied, among others, the structure of collaborations in research projects and journal articles (Meyer et al., 2004; Rigby \& Edler, 2005), academic research networks that facilitate academic publications (Lowrie \& McKnight, 2004; Abramo et al., 2009), and the relationship between social networks and academic career performance (Etzkowitz, 2000; Whittington \& Smith-Doerr, 2008). This paper develops a novel approach to analyse quantitatively the relationships among researchers, and between them and other social actors, by measuring their informal social networks. An informal network is formed by those links among social actors that do not follow prescribed official procedures and that, therefore, are not necessarily formalised through documents, formal reporting structures or organisational charts. This type of network includes working relations, collaborations and exchanges of resources and knowledge that are the result of personal initiatives among individuals who do not necessarily belong to the same formal organisational structures (Allen et al., 2007). 
Social network studies focus attention essentially on the structural properties of networks and on the value and consequences a specific position in the network has for the individual that holds it. In this paper we propose a different approach, which focuses additionally on the relational features of social networks. From the social networks perspective this approach has at times been labelled the "relational embeddedness" or “cohesive perspective" (Gulati, 1998). We expand a methodology that has been applied mainly in management studies (Uzzi, 1997; Ruef, 2002). For instance, Uzzi (1997) shows the existence of a link between patterns of inter-firm connections and indicators of industrial performance. In this study we show that a similar conceptual framework can be used as the basis of a quantitative analysis of the relationship between the structure of the social links that academics establish and research output.

The approach we pilot in this paper offers a quantitative tool for the analysis of the relationships established by members of academic institutions within and outside their own organisations, and of the association between the structure of these social linkages and the performance of academic functions.

The paper first introduces some key concepts derived from social network analysis and uses them to develop a set of hypotheses relating network patterns with individual research output. Next, we present our fieldwork and data set and explain the research techniques used for contrasting the hypotheses. Finally, we discuss the results and examine the implications of this research for the development of quantitative approaches to the analysis of Triple Helix relationships.

\section{Theoretical background and hypotheses}

This study aims to determine whether academic output may be related with the structure of scholars' social networks. The networks we are going to focus on are "first-order egocentred". An individual's first-order ego-centred social network consists of those other social actors with whom he or she maintains direct contact, and has some form of social bond (Adams, 1967). Following Nohria (1992) this network constitutes the most influential part of an actor's environment.

--Figure 1 about here-- 
Social networks are expected to exert an important influence on individual scientists' outcomes because they provide access to key resources for the development and improvement of their research activities and skills (Villanueva-Felez, 2011). The different access and exposure of individuals to those key resources, residing and flowing through the network, depends, however, on the pattern of the social structure in which the actor is embedded (Granovetter, 1985). Therefore, scientists' social networks differ from each other basically in two aspects (Burt, 1992; Ibarra, 1993; Burt, 1997; Gnyawali \& Madhavan, 2001):

a. Transactional contents: the quantity, quality and variety of resources that circulate through the different social structures.

b. The access, determined by the personal network characteristics, that a particular individual has to these flows of resources to accomplish his or her own objectives.

Consequently, a researcher's network will contribute to the enhancement of his or her own capabilities, and thus his or her scientific output, when the network's structural configuration provides the individual with improved accessibility to a wider range of resources. On the contrary, the network can have a negative influence or may constrain the performance of the researcher when it does not provide access to the required resources. This can be due to a "negative connectivity"2 between the network's nodes (Yamagishi et al., 1988), or to the poor quality or redundancy of the resources provided through the network (Granovetter, 1973; Burt, 1992).

\footnotetext{
${ }^{2}$ Negative connectivity emerges when the relations between one actor and another causes relations between the same actor and a third one to diminish. Yamagishi, Gillmore and Cook (1988: 835) define it as follows: "If two relations, A-B and B-C, are negatively connected at B, exchanges in the A-B relation diminish or prohibit exchanges in the $\mathrm{B}-\mathrm{C}$ relation, and vice-versa (e.g., a business meeting with A forces B to cancel a dinner appointment with C)" (1988: 835).
} 


\subsection{Embeddedness and research output}

Analysts have traditionally distinguished between strong and weak ties. Strong ties are based on trust, reciprocity and frequency of interaction (Granovetter, 1973; Krackhardt, 1992; Brass et al., 1998; Reagans \& Zuckerman, 2001). Trust facilitates cooperation and support among social actors (Brass et al., 1998), as well as transactions of resources and information (Krackhardt, 1992). When strong ties exist, individuals acquire detailed knowledge about each other's capabilities, attitudes, behaviours and objectives, and detailed and personalised information is exchanged. The time invested in the relationship generates the necessary experience that allows participants to predict (a) the contact's specific information need, and (b) how the shared information would be used by the partners (Krackhardt, 1992; Uzzi, 1997). As a result, strong links provide deeper and specific knowledge in a particular interest area for the individuals involved (Rowley et al., 2000) contributing to knowledge creation and dissemination of capabilities.

In contrast, weak ties are defined as casual acquaintances between social actors (Brass et al., 1998), characterised by infrequency of interaction (Granovetter, 1973) and based neither on trust nor reciprocity. However, these links can act as "local bridges" to other social circles beyond the individual's immediate social circle, providing new information about opportunities and the existence of other resources (Granovetter, 1973; McEvily \& Zaheer, 1999).

Embeddedness refers to the number of strong ties that an individual maintains in relation to the total number of links. Our study will analyse embeddedness of first-order egocentred networks. Following Uzzi (1997) we will distinguish three different types of networks depending on different patterns of embeddedness: overembedded, integrated and underembedded ${ }^{3}$.

A completely overembedded network has no weak ties. Individuals who develop an overembedded network invest all their time and resources on maintaining strong ties.

\footnotetext{
${ }^{3} \mathrm{We}$ are aware that these terms might be normative, in that they are not free of value. We have received suggestions to change this nomenclature to 'light', 'moderate' and 'high'. However, we have decided to maintain these terms to conform to the sources used (see UZZI, 1997).
} 
This causes two effects in the form and content of the social structure developed by the individual:

(a) a potentially smaller personal network, as the resources needed to maintain strong ties are bigger than for weak ties (Boorman, 1975), reducing the number of contacts that the actor can really sustain, and restricting the capacity to reach other social circles;

(b) an increment of redundant information flow, since as Granovetter (1973) points out, the strong links tend to connect among themselves reducing connections with external members who could contribute with innovative ideas (Burt, 1992).

Under these circumstances the social network becomes ossified and loses connection with the surrounding environment (Burt, 1992; Uzzi, 1997; Gnyawali \& Madhavan, 2001). Although overembedded networks increase cooperation, support and joint problem-solving between actors, their members have little contact with other social circles. For instance, an academic developing an overembedded network is likely to establish links with members of his or her own department, without ties with government, industrial, or other societal actors. One can hypothesise that this situation will narrow the perspective of a researcher and close him or her to potential developments of theoretical or methodological interest arising beyond the individual's immediate academic context.

In contrast, when the network is formed predominantly by weak ties, the network pattern is underembedded. In this situation network size is likely to be larger than in overembedded networks, allowing individuals to reach a variety of social circles. However, individuals with underembedded networks lack the advantages derived from the trust afforded by strong tie relations (Uzzi, 1997). Such networks tend to be unstable and less durable over time, causing the continuous reshaping of the social structure (Heracleous \& Murry, 2001). Nevertheless, Granovetter (1973) famously stated that weak ties are the bearers of novel and non-redundant information, indispensable for the discovery of new opportunities. Even so, in the academic research context, networks that do not foster cooperation and support between researchers, and consequently the transfer of tacit knowledge, might diminish both the quantity and the quality of research output.

Finally, an integrated network contains both strong and weak ties. This type of network combines the benefits generated by embeddedness and trust, like stable cooperation and 
support, while still ensuring a flow of novel information through weak ties (Uzzi, 1997). This network pattern is formed by a set of strong ties, which are stable, lasting and characterised by teamwork and joint problem-solving; and by a more dynamic, unstable and changing set of social relations (weak ties) providing the bridges to new methods, perspectives and ideas made in other sectors and social environments.

On the basis of the above, we establish the following hypothesis:

Hypothesis 1.1 Researchers with integrated network patterns will have higher research output than researchers with overembedded network patterns.

Hypothesis 1.2 Researchers with integrated network patterns will have higher research output than researchers with underembedded network patterns.

\subsection{Nodal heterogeneity and research output}

Embeddedness refers to the strength of links among actors but does not distinguish among the different types of actors with whom an individual is linked. First-order nodal heterogeneity refers to the variation in the mix of direct contacts in the social networks of individuals (McEvily \& Zaheer, 1999; Reagans \& Zuckerman, 2001). A range of nodal heterogeneity patterns can be identified, varying from completely homogeneous networks to completely heterogeneous structures.

Individuals with a heterogeneous network pattern have a broad variety of contacts that exposes them to diverse social circles, beyond their immediate circle. This allows them to reach a wider range of sources of information and opportunities (McEvily \& Zaheer, 1999). Thus, the higher the level of heterogeneity in a network, the larger the quantity, quality and variety of resources the actor can access. In universities, researchers with heterogeneous networks maintain links with members of other universities, and industrial and governmental organisations, both local, national and international.

This approach differs from the embeddedness perspective in that the origin of the variety of resources is not determined by the strength of the ties, but rather by the diversity of contacts. McEvily and Zaheer (1999) suggest that the sharing of a strong tie between two individuals does not necessarily imply the connection of these two individual's 
independent contacts as Granovetter (1973) predicts. In this perspective, the social circle reached by an actor's network is independent from the strength of the link.

--Figure 2 about here--

In contrast, a complete homogeneous network is characterised by the absence of bridging ties to other social circles, i.e. it is formed by nodes from the actor's most immediate social environment. McEvily and Zaheer (1999: 1137) argue that "bridging ties exist when high no redundancy, infrequency of interaction and geographic dispersion characterize (...)" the network. Thus a homogeneous network will have a redundancy of contacts, they will be linked between them, will interact frequently and all of them will be concentrated in a geographic area. Consequently, this type of network will lack weak ties and will present the same pattern associated with overembedded networks. The influence of homogeneous networks on an actor's actions, behaviour and, in the case of university departments, on his or her research output, would coincide with the features described for overembedded networks. Accordingly, we hypothesise:

Hypothesis 2.1 Researchers with the most heterogeneous network patterns will show the highest research output.

Hypothesis 2.2 Researchers with the most homogeneous network patterns will show the lowest research output.

\section{Research techniques}

\subsection{Sample and data collection}

Our respondents consist of 64 researchers from six departments from the University of Valencia (Spain), all of them with research interests related to business and management. The University of Valencia is a research-oriented university that fosters a policy of support and improvement in research quality and productivity. The selection of members from the same university and similar disciplines allows us to neutralise some cultural and institutional aspects that may affect the way researchers develop their networks patterns (Burt, 1997). 
Initially, we built a database of 183 academics with the information contained in the department's research activity official reports for the years 2003 and 2004. The population was distributed as follows: 18 professors, 153 lecturers, and 12 teaching assistants. In order to obtain data about the individual social network of the researchers, we conducted a survey. The preliminary survey instrument was tested by three academics in order to identify and correct any difficulties or misunderstandings in the wording of the questions. The main problems were the length of the questionnaire and the difficulties for respondents in identifying which of their contacts belonged to "industry" or "government". They were addressed in subsequent versions. Second and third versions of the questionnaire design were tested before the final version was defined. The final questionnaire was sent to the 183 individuals who comprised the identified population. Responses were received from 75 , that is a response rate of $41 \%$. Eleven questionnaires were rejected because they were incomplete. Consequently, a total of 64 responses are included in the following analysis, $35 \%$ of the initial population. ${ }^{4}$

\subsection{Measures}

\subsubsection{Research output}

The measurement of research outputs is a complex and controversial area of research. It is well known, for instance, that most measurements are very sensitive to contextual conditions: different disciplines display different publication and citation patterns. In part these problems are lessened here by the homogeneity of our group of reference: academics from the same discipline working in the same university.

Within this context, we develop a composite measure following the approach of Gulbrandsen \& Smeby (2005). They use a unique measure that takes into consideration both the quality and quantity of an individual's research output. It includes (1) papers in scientific and scholarly journals, (2) chapters in academic books or text books, and papers in conference proceedings, (3) academic books and textbooks, and (4) "popular

\footnotetext{
${ }^{4}$ Each one of the three types of academic appointment existing in the population (professors, lecturers and teaching assistants) is represented in the sample. Although the response rate among professors was lower than for the other two groups, with a 0.01 level of significance the sample is not biased. Further, we have not used these categories to analyse our data, and therefore our results are not affected by the lower rate of response among professors.
} 
science" articles. In order to consider output quality, publications were recorded to article equivalents. Following Gulbrandsen \& Smeby (2005) we develop a single composite indicator including the following items:

- $\quad$ papers presented at national research conferences (1 point);

- $\quad$ papers presented at international research conferences (2 points);

- articles published in national academic journals as well as chapters in academic books published in Spain (3 points);

- articles published in international academic journals and chapters in international academic books (4 points);

- $\quad$ academic books $(5 \text { points })^{5}$

For journal articles we assign double points for those published in indexed journals (both in Spain and internationally). We used the Thomson's ISI Journal Citations Report for the identification of indexed international publications and the In-Recs index for the Spanish journals ${ }^{6}$. The points assigned to co-authorships are divided by the total number of authors.

The resulting formula for Research Output (RO) is:

$\mathrm{RO}=[\mathrm{NatConf}+2 * \operatorname{IntConf}+3 *(\mathrm{NatArt}+2 *$ NatIndexArt $)+4 *(\operatorname{Int} A r t+2 * \operatorname{IntIndexArt})+5 * \mathrm{Bo}$ oks]/authors

\subsubsection{Degree of embeddedness}

The first-order degree of embeddedness is the relationship between strong ties and the total size of the direct links network. First, to develop an indicator of the degree of

\footnotetext{
${ }^{5}$ There was a single case of an author who published an academic book in English. If this had been valued using similar weights to the ones used for international journal articles (i.e. double the "points" of a domestic publication) the resulting distribution would have became skewed and prevented us from applying common statistical techniques. We treated this outlier case within a single, broader class of academic books, without making a distinction between national and international book publications.

${ }^{6}$ In-Recs (Social Science Spanish Journal citation report) has been created by "Evaluación de la ciencia y de la comunicación" research group, University of Granada. http://ec3.ugr.es/in-recs/
} 
embeddedness it is necessary to identify and measure strong ties. Many researchers consider that a tie is strong when it is based on trust, is reciprocal, and the social actors linked interact frequently (Granovetter, 1973; Krackhardt, 1992; Uzzi, 1996, 1997; Brass et al., 1998; Reagans \& Zuckerman, 2001). The set of strong links constitute the durable and stable part of an individual's network.

The academic research networks we study are composed of two types of relationships:

1. The research links that an academic maintains with other university academics and researchers; i.e. person-to-person relations.

2. The ties with firms and institutions from government and industry; i.e. person-toorganisation relations.

Therefore the measurement and identification of the strong ties in these two different contexts must take into account the differential nature of the relationship. To identify strong ties with other university researchers we asked the informants to indicate which of their contacts fulfilled both the following two characteristics:

a. The contact was seen as reliable, competent and would not behave in an opportunistic manner against the respondent. This condition expresses the features an individual must have for the actor to trust him/her (Mayer et al., 1995; Escribá-Esteve, 2002).

b. The contact and the respondent were used to working together and would communicate at least three times per month. This condition reflects strong interaction and reciprocity between the two actors (Uzzi, 1997).

To identify strong ties with industry and government organisations and institutions we required that the link be stable and multiplex. We asked the following closed question: "With whom would you maintain the link if your main contact person leaves the organisation?" The alternatives given were: a) only with the organisation, b) only with the person, c) with both and d) with none. Option $\mathrm{C}$ denotes strong links: even when the main contact person leaves the organisation, the relationship is maintained with both the organisation and the person. We take this view because, first, the relationship with that person is likely to be developed beyond the organisational limits; and second, because the bond with the organisation is not held only by one contact person. 
Once we identified the strong links, we calculated the degree of embeddedness as the relation between the sum of total strong ties and the first order network size. The resulting formula is:

$D E=\frac{S T u+\text { STorg }}{\text { TotalTies }}$

where, DE equals the degree of embeddedness, STu equals the total number of strong ties in the university/academia research arena, and STorg equals the total number of strong ties with organisations or institutions in other non-academic arenas (i.e. industry and government).

\subsubsection{Nodal heterogeneity}

First order nodal heterogeneity refers to the variation in the mix of contacts in the individuals' networks of direct links (McEvily \& Zaheer, 1999; Reagans \& Zuckerman, 2001). In order to estimate and measure nodal heterogeneity, we asked respondents to classify their contacts in relation to the following:

a. geographic location: distinguishing between local, national and international contacts,

b. institutional sphere: distinguishing between academic and non-academic contacts

We apply the following entropy measure (Shannon \& Weaver, 1959) to the two dimensions above (geographical and institutional) to calculate network heterogeneity:

$\mathrm{D}=-\left(\frac{1}{\log (\mathrm{n})}\right) \sum_{\mathrm{i}=1}^{\mathrm{n}} \mathrm{y}_{\mathrm{i}} \log \left(\mathrm{y}_{\mathrm{i}}\right)$

where, $D=$ diversity, $n$ is equal to the social categories considered, $y_{i}$ is the proportion of contacts listed by the respondent within each category $i$.

This measure varies from 0 for complete homogeneity, i.e. all contacts in the network belong to the same social category; to 1 for complete heterogeneity, i.e. each social category considered has the same number of contacts. 


\subsection{Analysis}

Our method uses different research techniques for the identification of network structures. First, we use percentile ranks to identify patterns in relation to the degree of embededdness. Percentiles are used to describe the characteristics of a distribution and indicate the relative position of an individual within a dataset. Second, we applied cluster analysis to determine nodal heterogeneity patterns of the researchers' networks. As Hair et al. (1998: 481) argued "the primary goal of cluster analysis is to partition a set of objects into two or more groups based on the similarity of the objects for a set of specified characteristics." This allows us to identify underlying structures and to simplify complex sets of data for further analysis and interpretation.

Once we identified groups of researchers with different network patterns, we used MannWhitney $U$ test for independent populations to compare the research outputs of the different groups. This test requires no specific assumption regarding the distribution of research output, allowing us to identify relationships between network relational structures and our research outputs indicator.

\section{Results and discussion}

\subsection{Degree of embeddedness and research output.}

According to Uzzi (1997) three different types of network patterns can be determined relying on the degree of embeddedness shown - overembedded, integrated and underembedded networks. The $25^{\text {th }}$ percentile scored a value equal to $33.3 \%$ of strong links in the network composition and the $75^{\text {th }}$ percentile a $71.4 \%$ of strong links. We grouped academics according to those values, given as a result the three groups shown in Table I.

--Table I about here--

We observe that the first group displays an overembedded network pattern as, on average, $92 \%$ of their contacts are maintained through strong ties. Conversely, the average proportion of strong links for individuals in the third group is only $25 \%$, thus 
displaying an underembedded network pattern. Finally, the second group displays a more even distribution between strong and weak ties, indicating an integrated network pattern.

To test the hypothesis about the relationship between the different network relational structures identified above and academic research output, we use Mann-Whitney U test. Table I shows the average research output for the groups displaying different degrees of embeddedness. The individuals who display a more integrated network pattern have a better research performance than those researchers with either overembedded or underembedded network patterns. Table I also shows that overembedded network patterns are associated with the lowest average research output.

It is now necessary to test whether these differences are significant. Table II shows the significance values obtained by the application of Mann-Whitney test procedures. For a significance level of $\alpha=0.1$, those individuals that maintain a balance between strong and weak ties in their networks (integrated networks) have a significantly better research performance than researchers with overembedded networks. However, the MannWhitney test does not suggest significant differences for those researchers whose networks are underembedded.

--Table II about here--

The results allow us to confirm hypothesis 1.1 and 1.2 at an acceptable level of significance. Additionally, although individuals with an underembedded network show higher research output values than individuals with overembedded network patterns, the differences obtained are not significant.

\subsection{Nodal heterogeneity and research output}

We initially used Two Step Cluster Analysis and Hierarchical Cluster Analysis to determine network relational structures with regard to nodal heterogeneity. The first cluster method offered a solution with three clusters, while the hierarchical method showed one group more. To solve this problem we used a third cluster technique, KMeans Cluster Analysis, to compare the results of different clustering techniques. As KMeans Cluster Analysis allows us to specify the number of clusters in advance, we ran the simulation first with three groups and afterwards with four groups. We decided to choose the 4 groups K-Means Cluster solution because it distributed the objects more 
equitably between the different groups and showed larger distances between the cluster centres.

--Table III about here--

Table III shows four groups with four network patterns. The values of the entropy measures range from 0 to 1 , where 0 denotes no heterogeneity at all (complete homogeneity), and 1 indicates complete heterogeneity.

--Table IV about here--

Table IV presents more detail on the characteristics of the contacts that the different groups display. Group 1 presents a completed homogeneous pattern with regard to both geographic diversity (all the contacts are local) and institutional diversity (no links outside academia). Therefore, members of this group develop a research network consisting of members of their own university department only. Group 2 shows more geographic diversity than group 1 (they have university contacts both in their department and in other departments and they also have more international contacts) but a high degree of institutional homogeneity (98\% of their contacts belong to the University arena). Members of group 3 concentrate their contacts locally (almost 70\% of their links are local). Nevertheless, this group shows the largest diversity concerning the institutional distribution of their contacts. They have the highest percentage of ties with actors from the industrial and governmental spheres (around 34\% of their links). Group 4 represents a high heterogeneity in both dimensions. It displays the most internationalised network pattern, with around $16 \%$ of their links being international, mainly with other academics $(11 \%)$. However, as with the rest of the groups, they develop more contacts in the local academic sphere.

Again, to test the hypothesis about the relationship between the different network relational structures identified above and academic research output, we use MannWhitney U test. Table III presents research output means for all groups obtained in relation to nodal heterogeneity. Individuals from group 2 and from group 3 achieve similar research outputs. Group 1, with complete homogeneity of network patterns in both geographic and institutional dimensions, presents the lowest research output mean. In contrast, group 4 has both the highest research performance and the highest network pattern heterogeneity. However, not all the differences across groups are significant. 
--Table V about here--

Table $\mathrm{V}$ shows the significance values obtained through the application of MannWhitney U test. Group 1 (individuals with homogeneous network patterns) have significantly lower research output than the rest of the groups; therefore, hypothesis 2.2 is confirmed. However, we cannot confirm hypothesis 2.1 as the group with highest total heterogeneity (group 4) does not present a significantly higher research output mean than groups 2 or 3 . Although some degree of heterogeneity in the network structure appears to be associated with a higher research output, we are not able to determine which kind of network diversity (i.e. based on geographic or on institutional heterogeneity or both) is more strongly related with better research output. ${ }^{7}$

\section{Conclusions}

This paper has shown how social network analysis techniques can be combined with other statistical tools to explore the networks that academics establish among themselves and with non-academics. Our approach provides additional insights into the structure of social networks; in particular, it reveals the internal variation within groups that, in other studies, have been treated as a unit. Analysis at higher levels of aggregation (including departmental) would have glossed over the important differences that emerge at the level of the individual even within the same discipline and cultural and institutional contexts (Burt, 1997). This is not, in itself, a novel discovery. Qualitative studies have often drawn attention to the importance of the activities of specific individuals, and there is also substantial quantitative literature correlating, for instance, the academic performance of individuals with other individual characteristics. Yet, what the paper shows is that quantitative techniques can be extended to the analysis of social relationship patterns at the individual level, and that these techniques can be used as a tool to investigate the nature of the links within and outside academia, and to relate these links with other variables.

\footnotetext{
${ }^{7}$ A possible explanation for this lack of differentiation could lie on similar network transitivity. Network transitivity occurs when an individual acquires competences from another to interact independently with a third individual (Uzzi \& Gillespie, 2002). In other words, transitivity could act as a measure of the "social capital" available through an individual's network nodes. However, to measure network transitivity it would be necessary to analyse second order networks. This falls outside of the scope of this paper.
} 
In this paper we have illustrated the potential of the techniques by exploring the relationships between the types of social networks that academics establish and their academic performance. We have shown that the characteristics of a researcher network are related with his or her academic research output. Specifically, our results suggest that researchers who are part of an integrated network, with a mix between strong and weak ties, achieve better research outputs. Overembedded networks are related with lower academic output. The same can be said of researchers with completely homogeneous networks: they display the poorest academic output results. Nodal heterogeneity is positively and significantly related with research output.

Our results offer further evidence in support of the Triple Helix model and are consistent with results obtained in previous studies using different techniques. Etzkowitz (2000) shows that an "intermediate" number of strong ties in the networks of academics affect scientific productivity positively. ${ }^{8}$ Our results strengthen the view that researchers who establish social networks combining both strong and weak ties are also more adept at academic knowledge creation. This outcome is also consistent with the extant social network analysis literature. These network structures combine the advantages derived from both types of links while minimising the limitations and threats of underembedded and overembedded social networks (Uzzi, 1997).

Our paper has presented a somewhat narrow and limited application of the analytical techniques we propose. Replication across different institutional, regional and academic environments would allow us to determine whether the patterns identified here are contingent to the specific academic, institutional and cultural context in which our study is framed, or can be generalised across different environments.

${ }^{8}$ However, Etzkowitz measures the strength of a tie in a different way. See Etzkowitz (2000:165) 


\section{References}

Abramo, G., D’Angelo, C., \& Di Costa, F. 2009. Research collaboration and productivity: is there correlation? Higher Education, 57: 155-171.

Adams, B. N. 1967. Interaction Theory and the Social Network. Sociometry, 30(1): 64-78.

Allen, J., James, A. D., \& Gamlen, P. 2007. Formal versus informal knowledge networks in R\&D: a case study using social network analysis. R\&D Management, 37(3): 179-196.

Boorman, B. 1975. A combinational optimization model for transmission of job information through contact networks. Bell Journal of Economics, 6(1): 216-249.

Brass, D. J., Butterfield, K. D., \& Skaggs, B. C. 1998. Relationships and unethical behavior: A social network perspective. Academy of Management. The Academy of Management Review, 23(1): 14-31.

Burt, R. S. 1992. Structural Holes: The Social Structure of Competition. Cambridge: Harvard University Press.

Burt, R. S. 1997. The contingent value of social capital. Administrative Science Quarterly, 42(2): 339-365.

Escribá-Esteve, A. 2002. Procesos de generación de confianza en los acuerdos de cooperación. Cuadernos de Economía y Dirección de la Empresa, 13: 469-497.

Etzkowitz, H. 2000. Athena Unbound: The Advancement of Women in Science. Port Chester, NY, USA: Cambridge University Press.

Etzkowitz, H., \& Leydesdorff, L. 2000. The dynamics of innovation: from National Systems and "Mode 2" to a Triple Helix of university-industry-government relations. Research Policy, 29(2): 109-123.

Gnyawali, D. R., \& Madhavan, R. 2001. Cooperative networks and competitive dynamics: A structural embeddedness perspective. Academy of Management. The Academy of Management Review, 26(3): 431-445.

Granovetter, M. 1973. The Strength of Weak Ties. American Journal of Sociology, 78(6): 1360-1380.

Granovetter, M. 1985. Economic Action and Social Structure: The Problem of Embeddedness. American Journal of Sociology, 91(3): 481-510.

Gulati, R. 1998. Alliances and networks. Strategic Management Journal (1986-1998), 19(4): 293-317.

Gulbrandsen, M., \& Smeby, J.-C. 2005. Industry funding and university professors' research performance. Research Policy, 34(6): 932-950.

Hair, J. F., Anderson, R. E., Tatham, R. L., \& Black, W. C. 1998. Multivariate Data Analysis (Fifth ed.). Upper Saddle River, NJ, USA: Prentice-Hall International, Inc.

Heracleous, L., \& Murry, J. 2001. Networks, interlocking directors and strategy: Toward a theoretical framework. Asia Pacific Journal of Management, 18(2): 137-160.

Ibarra, H. 1993. Network centrality, power, and innovation involvement: Determinants of technical and administrative roles. Academy of Management Journal, 36(3): 471-501.

Krackhardt, D. 1992. The strenght of strong ties: The importance of philos in organizations. In N. Nohria, \& R. G. Eccles (Eds.), Networks and Organizations: 216-239. Boston: Harvard Business School Press. 
Lowrie, A., \& McKnight, P. J. 2004. Academic Research Networks: A Key to Enhancing Scholarly Standing. European Management Journal, 22(4): 345-360.

Mayer, R. C., Davis, J. H., \& Schoorman, F. D. 1995. An integration model of organizational trust. Academy of Management. The Academy of Management Review, 20(3): 709-734.

McEvily, B., \& Zaheer, A. 1999. Bridging ties: A source of firm heterogeneity in competitive capabilities. Strategic Management Journal, 20(12): 1133-1156.

Meyer, M., Morlacchi, P., Persson, O., Archambault, E., \& Malsch, I. 2004. Continuous professional development in emerging technology sectors, A SPRU Report for the Engineering and Technology Board: 1-60: SPRU - University of Sussex.

Molas-Gallart, J., Tang, P., \& Morrow, S. 2000. Assesing the non-academic impact of grant-funded socio-economic research: research from a pilot study. Research Evaluation, 9(3): 171-182.

Nohria, N. 1992. Is a network perspective a useful way of studing organizations? In N. Nohria, \& R. G. Eccles (Eds.), Networks and Organizations: 1-22. Boston: Harvard Business School Press.

Reagans, R., \& Zuckerman, E. W. 2001. Networks, diversity, and productivity: The social capital of corporate R\&D teams. Organization Science, 12(4): 502-517.

Rigby, J., \& Edler, J. 2005. Peering inside research networks: Some observations on the effect of the intensity of collaboration on the variability of research quality. Research Policy, 34(6): 784-794.

Rowley, T. J., Behrens, D., \& Krackhardt, D. 2000. Redundant Governance Structures: Analysis of Structural and Relational Embeddedness in the Steel and Semiconductor Industries. Strategic Management Journal, 21(3): 369-386.

Ruef, M. 2002. Strong ties, weak ties and islands: Structural and cultural predictors of organizational innovation. Industrial and Corporate Change, 11(3): 427-449.

Shannon, C. E., \& Weaver, W. 1959. The Mathematical Theory of Communication [1949]: University of Illinois Press: Urbana, IL.

Uzzi, B. 1996. The sources and consequences of embeddedness for the economic performance of organizations: The network effect. American Sociological Review, 61(4): 674-698.

Uzzi, B. 1997. Social structure and competition in interfirm networks: The paradox of embeddedness. Administrative Science Quarterly, 42(1): 35-67.

Uzzi, B., \& Gillespie, J. J. 2002. Knowledge spillover in corporate financing networks: Embeddedness and the firm's debt performance. Strategic Management Journal, 23(7): 595.

Villanueva-Felez, A. 2011. El acceso a recursos desde una perspectiva relacional: Un análisis contingente de las características de los vínculos sociales. Unpublished Dissertation, Universidad de Valencia, Valencia.

Whittington, K. B., \& Smith-Doerr, L. 2008. Women Inventors in Context: Disparities in Patenting across Academia and Industry. Gender Society, 22(2): 194-218.

Yamagishi, T., Gillmore, M. R., \& Cook, K. S. 1988. Network Connections and the Distribution of Power in Exchange Networks. The American Journal of Sociology, 93(4): 833-851. 


\section{Tables \& Figures}

Figure 1: Ego-centred network.

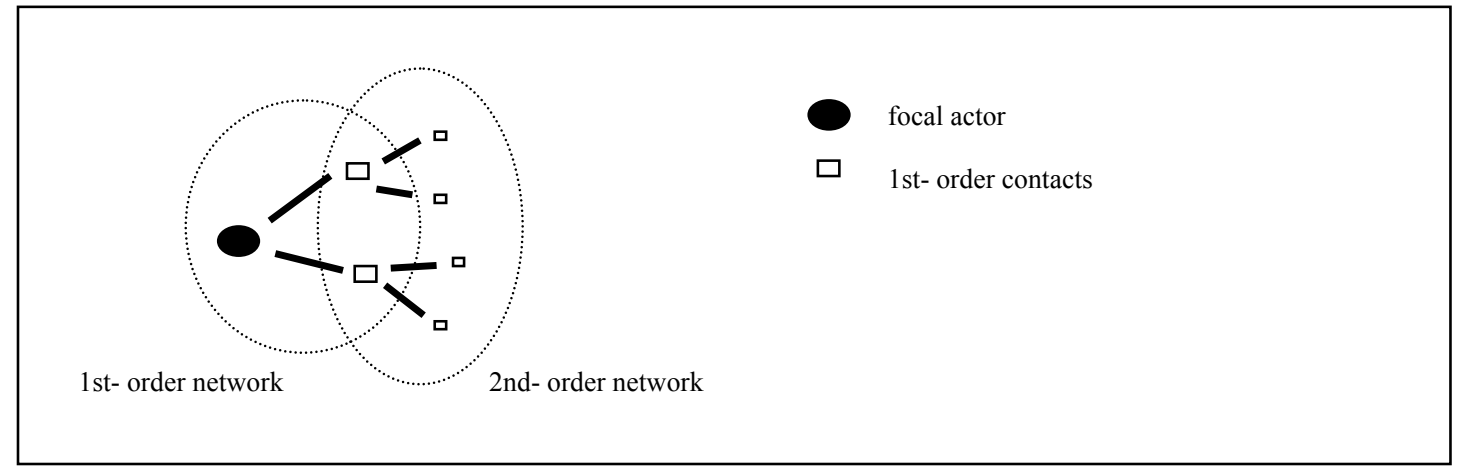

Source: UZZI, 1997.

Figure 2: Heterogeneous and homogeneous networks

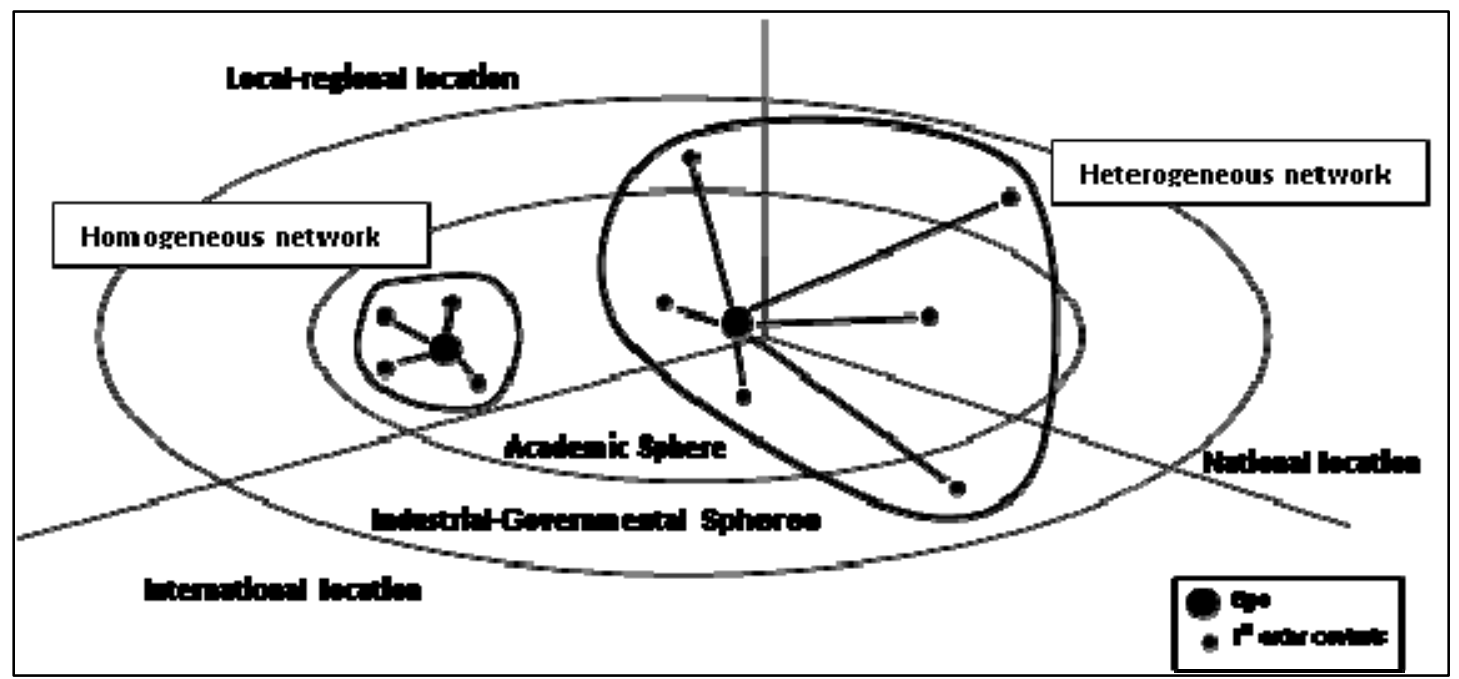

Table 1: Descriptive - Degree of embeddedness

\begin{tabular}{lccc}
\hline & $\mathrm{N}$ & $\begin{array}{c}\text { Degree of } \\
\text { embeddedness mean }\end{array}$ & $\begin{array}{c}\text { Research output } \\
\text { mean }\end{array}$ \\
\hline Group 1 - Overembedded network & 13 & .9214 & $\mathbf{2 . 9 6 3 1}$ \\
\hline Group 2 - Integrated network & 32 & .5960 & $\mathbf{8 . 0 0 8 8}$ \\
\hline Group 3 - Underembedded network & 19 & .2491 & $\mathbf{4 . 3 7 6 8}$ \\
\hline
\end{tabular}


Table 2: Mann-Whitney U test - Degree of embeddedness

\begin{tabular}{ccc}
\hline GROUPS & $\mathrm{U}$ & Sig. (1-tailed) \\
\hline $1-2$ & 131.5 & $0.027^{*}$ \\
\hline $1-3$ & 94.0 & 0.127 \\
\hline $2-3$ & 235.5 & $0.063^{\dagger}$
\end{tabular}

${ }^{*} \mathrm{p}<0.05$ level; ${ }^{\dagger} \mathrm{p}<0.1$

Table 3: Descriptive - Nodal Heterogeneity

\begin{tabular}{cccccc}
\hline Group & $\mathrm{N}$ & $\begin{array}{c}\text { Geographic } \\
\text { diversity }\end{array}$ & $\begin{array}{c}\text { Institutional } \\
\text { diversity }\end{array}$ & $\begin{array}{c}\text { Total } \\
\text { heterogeneity }\end{array}$ & $\begin{array}{c}\text { Research output } \\
\text { means }\end{array}$ \\
\hline 1 & 9 & .000 & .000 & $\mathbf{0 . 0 0}$ & $\mathbf{1 . 5 0 4 4}$ \\
\hline 2 & 21 & .683 & .096 & $\mathbf{0 . 3 9}$ & $\mathbf{6 . 4 8 2 9}$ \\
\hline 3 & 19 & .517 & .882 & $\mathbf{0 . 7 0}$ & $\mathbf{6 . 1 6 7 4}$ \\
\hline 4 & 15 & .847 & .793 & $\mathbf{0 . 8 2}$ & $\mathbf{9 . 1 3 4 7}$ \\
\hline
\end{tabular}

Table 4: Contacts means distribution per groups

\begin{tabular}{llcccc}
\hline Means & & Group 1 & Group 2 & Group 3 & Group 4 \\
& & $\mathrm{N}=9$ & $\mathrm{~N}=21$ & $\mathrm{~N}=19$ & $\mathrm{~N}=15$ \\
\hline \% local nodes & & 1.0000 & .4395 & .6973 & .5153 \\
\% national nodes & & .0000 & .4124 & .2147 & .3254 \\
\% international nodes & & .0000 & .1481 & .0889 & .1594 \\
\hline \% academic nodes & & 1.0000 & .9815 & .6553 & .7269 \\
\% non-academic nodes & & .0000 & .0185 & .3447 & .2731 \\
\hline \multirow{2}{*}{ \% LOCAL nodes } & ACAD & 1.0000 & .4238 & .3905 & .3600 \\
& Non-ACAD & .0000 & .0157 & .3068 & .1553 \\
\hline \multirow{2}{*}{ \% NATIONAL nodes } & ACAD & .0000 & .4110 & .1868 & .2547 \\
& Non-ACAD & .0000 & .0014 & .0279 & .0707 \\
\hline \multirow{2}{*}{ \% INTERNATIONAL } & ACAD & .0000 & .1467 & .0784 & .1127 \\
& Non-ACAD & .0000 & .0014 & .0105 & .0467 \\
\hline
\end{tabular}

Table 5: Mann-Whitney U test - Nodal heterogeneity

\begin{tabular}{ccc}
\hline GROUPS & U & Sig. (2-tailed) \\
\hline $1-2$ & 51.5 & $0.048^{*}$ \\
\hline $1-3$ & 28.5 & $0.005^{* *}$ \\
\hline $1-4$ & 20.0 & $0.004^{* *}$ \\
\hline $2-3$ & 184.5 & 0.684 \\
\hline $2-4$ & 126.5 & 0.319 \\
\hline $3-4$ & 119.0 & 0.415 \\
\hline
\end{tabular}

$* * \mathrm{p}<0.01 ; * \mathrm{p}<0.05$ 


\section{AppendixA: Survey Format}

NAME:

1. Which year did you start working at the University? year.

\section{RELATIONSHIPS WITHIN ACADEMIA}

\section{LOCAL LEVEL}

2. Indicate the total number of contacts in your own department with whom you have discussed or commented topics and issues related to your own research, in the last two years.

TOTAL DEPARTMENT: contacts.

3. Consider the following two possible characteristics about the contacts with whom you discuss aspects related to your research:

a. Your contact is reliable (accomplishes his/her commitments), is competent and would not behave in an opportunistic manner towards you.

b. Your contact and you are used to working together and communicating at least three times per month.

3.1 How many of your contacts in the department (Question 2) fulfil the TWO characteristics above: Number: contacts that fulfil the two characteristics.

3.2 How many of your contacts in the department (Question 2) fulfil the just ONE (and only one) characteristic above: Number: people that fulfil just one characteristic.

3.3 How many of your contacts in the department (Question 2) do not fulfil any of the two characteristics: Number: people that do not fulfil any characteristic.

NATIONAL LEVEL

4. Indicate the total number of contacts from Spanish academic and research institutions with whom you have discussed or commented topics and issues related to your own research, in the last two years.

TOTAL NATIONAL: contacts.

5. Consider the following two possible characteristics about the contacts with whom you discuss aspects related to your research:

a. Your contact is reliable (accomplishes his/her commitments), is competent and would not behave in an opportunistic manner towards you.

b. Your contact and you are used to working together and communicating at least three times per month.

5.1 How many of your contacts in Spanish academic institutions (Question 4) fulfil the TWO characteristics above: Number: contacts that fulfil the two characteristics.

5.2 How many of your contacts in Spanish academic institutions (Question 4) fulfil the just ONE (and only one) characteristic above: Number: people that fulfil just one characteristic.

5.3 How many of your contacts in Spanish academic institutions (Question 4) do not fulfil any of the two characteristics: Number: people that do not fulfil any characteristic.

\section{INTERNATIONAL LEVEL}

6. Indicate the total number of contacts from international academic and research institutions with whom you have discussed or commented topics and issues related to your own research, in the last two years.

TOTAL INTERNATIONAL: contacts.

7. Consider the following two possible characteristics about the contacts with whom you discuss aspects related to your research:

a. Your contact is reliable (accomplishes his/her commitments), is competent and would not behave in an opportunistic manner towards you.

b. Your contact and you are used to working together and communicating at least three times per month.

7.1 How many of your contacts in international academic institutions (Question 7) fulfil the TWO characteristics above: Number: contacts that fulfil the two characteristics.

7.2 How many of your contacts in international academic institutions (Question 7) fulfil the just ONE (and only one) characteristic above: Number: people that fulfil just one characteristic.

7.3 How many of your contacts in international academic institutions (Question 7) do not fulfil any of the two characteristics: Number: people that do not fulfil any characteristic. 


\section{RELATIONSHIPS WITH PRIVATE SECTOR AND NGO'S}

Indicate with initials or names the firms and non- governmental organizations with which you maintain or have maintained an academic-professional relationship in the years 2004 and 2005.
In which city or region do you normally meet or have met with these firms or organisations?
With whom would you maintain the relationship if your main contact person leaves the organisation?

You would maintain:

(Tick the appropriate one)

\begin{tabular}{|l|l|l|}
\hline INITIALS & CITY-REGION & $\begin{array}{l}\text { If my main contact person leaves the firm/organization, I } \\
\text { MANTAIN the relationship with.... }\end{array}$ \\
\hline 1. & $\square$ just the firm/organisation $\square$ just the person $\square$ both $\square$ none \\
\hline 2. & & $\square$ just the firm/organisation $\square$ just the person $\square$ both $\square$ none \\
\hline 3. & $\square$ just the firm/organisation $\square$ just the person $\square$ both $\square$ none \\
\hline 4. & $\square$ just the firm/organisation $\square$ just the person $\square$ both $\square$ none \\
\hline 5. & $\square$ just the firm/organisation $\square$ just the person $\square$ both $\square$ none \\
\hline 6. & $\square$ just the firm/organisation $\square$ just the person $\square$ both $\square$ none \\
\hline
\end{tabular}

\section{RELATIONSHIPS WITH GOVERMENTAL INSTITUTIONS}

Indicate with initials or name the governmental organizations or institutions with which you maintain or have maintained an academicprofessional relationship in the years 2004 and 2005.

\begin{tabular}{|c|c|c|}
\hline INITIALS & SCOPE & $\begin{array}{l}\text { If my main contact person leaves the } \\
\text { institution/organization, I MANTAIN the relationship } \\
\text { with.... }\end{array}$ \\
\hline 1. & $\square$ Local-Regional $\square$ National $\square$ International & $\square$ just the institution $\square$ just the person $\square$ both $\square$ none \\
\hline 2. & $\square$ Local-Regional $\square$ National $\square$ International & $\square$ just the institution $\square$ just the person $\square$ both $\square$ none \\
\hline 3. & $\square$ Local-Regional $\square$ National $\square$ International & $\square$ just the institution $\square$ just the person $\square$ both $\square$ none \\
\hline 4. & $\square$ Local-Regional $\square$ National $\square$ International & $\square$ just the institution $\square$ just the person $\square$ both $\square$ none \\
\hline 5. & $\square$ Local-Regional $\square$ National $\square$ International & $\square$ just the institution $\square$ just the person $\square$ both $\square$ none \\
\hline 6. & $\square$ Local-Regional $\square$ National $\square$ International & $\square$ just the institution $\square$ just the person $\square$ both $\square$ none \\
\hline
\end{tabular}

